\title{
Implementation of the Code of Ethics in Social Services
}

\section{Ludvigh Cintulova (Lucia Ludvigh Cintulova)', P. Beno (Pavol Beno)²}

${ }^{1}$ St. Elizabeth University of Health and Social Sciences, SK

${ }^{2}$ Faculty of Health and Social Work, Trnava University in Trnava, SK

\section{E-mail address:}

luciacin83@gmail.com

\section{Reprint address:}

Lucia Ludvigh Cintulova

St. Elisabeth University of Health and Social Sciences

Nam. 1. Maja 1

81000 Bratislava

SK

Source: Clinical Social Work and Health Intervention

Pages: $14-19$

Volume: 9

Issue: 2

\section{Reviewers:}

Anna Beresova

Pavol Jozef Safarik University in Kosice, SK

Maria Mojzesova

St. Elizabeth University of Health and Social Sciences, SK

\section{Key words:}

Ethical behavior. The Code of Ethics. Ethical Standards. Social Services.

\section{Publisher:}

International Society of Applied Preventive Medicine i-gap

CSWHI 2018; 9(2): 14 - 19; DOI 10.22359/cswhi_9_2_02 @ 2018 Clinical Social Work and Health Intervention

\section{Abstract:}

Objective: The research aim was focused on an analysis of problems of ethical behavior in Social Work. We did research aimed at asking questions, how the ethical standards are implemented in daily life of Social Workers in link with her/his profession and the standards of the quality of Social Services due to Social Services.

Design: We did collection of research data from March to May 2017, through structural individual interviews with Social Workers in Daily 
Care Centers; the answers were analyzed by open coding and we made practical recommendations based on these research results.

Participants: Social Work is predominantly represented by women, with an average age of 41.7 years compared to men 48.5 years. The average length of female practice is almost 10 years, compared to men with over 5 years.

Methods: We did open coding of data collected from participants using qualitative research method.

Results: Data analysis has shown the following key findings: the implementation of the Code of Ethics in Social Services and respect for human rights while working with clients is highly dependent on the management of the organization; human and personal capital; subjective feelings of burnout syndrome; work atmosphere or conditions of providing Social Services. Research has shown a great quality of Social Services depend on value orientation and the professionalism of a Social Worker; as well as meeting the needs of clients depends on the management of the organization charged with providing Social Services.

Conclusion: Strong abilities and commitment to perform ethically in the self-helping professions is the basis of the quality of service provided to clients; reflecting other factors such as mutual relationship; trust; professionalism; access to services; ethical standards; autonomy and honorable respect.

\section{Introduction}

The formulation of the Code of Ethics as a basic requirement for professionalism and the quality of helping professions has been in progress. The Code itself does not guarantee the ethical behavior of Social Workers which depends on the responsibility of the individual Social Workers in regard to their profession. This paper is focused on the implementation of standards of the Social Work Code of Ethics in the field of Social Services including direct contact with the clients in need. Social Workers often meet with ethical dilemmas presented in society: on the one hand there are needs and benefits of vulnerable people and on the other hand the question of covering costs, spending money effectively and the range of providing Social Services in local communities. (According to IFSW / IASSW, 2004).

\section{Participants and Methods}

The research project was based on implementation of ethical principles and standards in Social Services as a basic attribute to carry on Social Work and provide services to people in need. The implementation of the Code of Ethics influences the quality of Social Work as well as common life of clients. The main research aims consisted of these priorities:

- to analyse the keeping of ethical principles in the work with clients receiving Social Services;

- to analyse the possible impact of ethical principles on the quality of Social Services, including standards such as respect of dignity; individual approach; empowerment of clients of Social Services; the primacy of client's interests; respect of private information; 
- to analyse how using ethical standards in Social Service might influence the professional relationship between Social Workers and clients and the building of the mutual trust.

We collected the research data from March to May 2017 through structural interviews with Social Workers in four Daily Care Centers in the Trnava Region; the answers were analyzed by open coding and we made practical recommendations based on these research results. The research sample consisted of 30 Social Workers in direct contact with clients all seniors. Social Work is predominantly represented by women, with an average age of 41.7 years compared to men 48.5 years. The average length of female practice is almost 10 years, compared to men with over 5 years. The results have shown the Social Workers (women) spend about 2.4 hours in direct contact with clients compared to 5.6 hours of secondary work; the rest of the day includes paper work, providing service and administrative. The results show that men spend less time with clients, about 1.3 hours per day and the rest of time they take care of providing secondary work connected with Social Services in the Social Care Center. The research has shown the high number of clients per each Social Worker; the average number is 13-15 clients per Social Worker depending on the size of the Social Services Facility in which they perform the Social Work.

\section{Results}

In the research, we focused on the connection in the protection of human rights and dignity of users of Social Services in care centers; professionalism of Social Workers and the implementation of Code of Ethics in the practice.

\section{Research question: What are the most common ethical dilemmas in the Social Work Practice with the elderly users of Social Services?}

The results had shown the most frequent dilemmas in the professional work of Social Workers in Daily Care Centers which can be summarized into following categories:

\section{The issue of power in Social Work Practice and powerlessness/ dependence of clients}

Each Social Worker should empower a client to make use of her/his abilities and strengths; on the other hand, due to health status, age, motivation, and weaknesses most of the older client's being dependent on the help of other people are not able to control their lives. Their lack of power derives from their dependency and the Social Worker becomes a authority to manage their lives thus having much more impact on their lives than older people might wish. The survey showed that the power of Social Workers can generate a lack of motivation, meaninglessness, distress, cynicism in the Seniors, because the clients feel to be controlled and under power of the Social Workers.

\section{The issue of having respect and being respected}

The old people who live apart from the rest of society or live in Social Care Centers, or who are not respected or granted ordinary dignities and courtesies accorded to others begin to doubt their own worth. The seniors are dependent on their experiences with others and also with Social Workers for clues to how they should view and value themselves. The seniors feel loneliness, even when in touch with others in the Care Center due to strict programs; residual care; 
time table of activities; the narrow time management of Social Workers.

\section{The issue of fulfilment of individual plans and real abilities of clients}

Social Workers take on a variety of responsibilities that should ultimately serve their clients' best interests. One of them is to achieve goals of individual plans suited to the needs and interests of seniors. The Social Workers create individual plans - most of them just on the paper because there is no time to make them actual in practice due to the large number of clients; timetables; space, motivation and so on.

\section{The issue of motivation and empowerment}

Seniors often feel alienated - separated from society due to their lack of an active life; failing in obtaining new life goals; being needed by others. Because of these factors, they are more likely to express powerlessness. Social Workers have to put much more effort to motivate the seniors to be active and to empower their abilities while avoiding making them exhausted and burned out.

\section{The issue of respecting rights}

Social Workers often face the client's right to self-determination. Seniors are ultimately in charge of making their own decisions and finding solutions to problems, regardless of whether a Social Worker agrees with their course of action. A Social Worker may provide guidance and help them explore their options, but she or he may not allow their own opinions and personal biases to influence their clients. This is a difficult dilemma that is created by the Social Worker's desire to act in the client's best interest and the need to respect their right to act in a way that they feel is best.

\section{The issue of needs of clients and interests of the Social Facility}

Social Workers in Practice often face ethical dilemmas connecting clients' interests and management issues. A Social Worker is a person who should help vulnerable people and empower their abilities as much as possible to become independent. On the other hand, a vulnerable person is dependent on the services provided by the Social Facility more clients mean more money. It is a great ethical dilemma to harmonize clients' needs and the requirements that must be covered by Social Services Facility perspectives: to manage staff; budget costs; provide Social Services and other technical services, all in favor of the clients.

\section{The issue of participation and cooperation}

Social Workers admit that the Social Facility may not cooperate; management being afraid of competition. They said it is a pity because clients suffer from mutual fights and achieving power in the society and the quality of Social Services does not increase. In most cases, the interest of the organization may be preferred to needs of clients.

\section{The issue of marketing and know-how}

Social Workers sometimes think that the issue of marketing and using good knowhow is more important than satisfaction of their clients. The Social Facilities should not behave as though the corporation knows best. On the other hand, marketing strategies and interesting communication help them to achieve fundraising success. And, Social Facilities are more open to social media; they publish photos showing the social activities in the Center, promote their daily programs and ask for donations using clients as magnets for sponsors. 


\section{Discussion}

Social Workers can help individuals, families and communities build on their strengths and unlock their potentials, for example, by supporting older people to begin volunteering, thus ensuring that other care users are not isolated. Social Workers meet with ethical dilemmas every day, but it is up to them how they can handle them and change the thinking of society. From the prosocial values point of view, Social Workers should match clients' interests first, than be managers of Social Services.

While respecting clients' rights, Social Workers must be aware of not viewing seniors as just an object of a pity or care; but seeing the clients worthy to have equal status; opportunities to live active, independent lives; having the right to make their own decisions in the process of individual self-development. (Guran et al, 2015).

Research conducted by Blom and Moren (2012) based on the quality of work in Social Work Practice had shown that from different perspectives there were significant differences between the quality of Social Services provided and the quality of life of the clients themselves. The research confirmed that it is important to recognize the differences between the quality of Social Services and the quality of life of clients. According to the respondents, for clients, the quality of their lives is greatly influenced by the ethical attitudes of Social Workers. The research confirmed the connection between ethical and emphatic approaches of Social Worker and the quality of the Social Services. If the Social Worker is keen on practicing ethical and moral standards in common life, than she/ he is more willing to be helpful and open to client's needs, feelings and interests.
Schrader-McMillen \& Stevard-Brown (2011) focused on the quality of Social Services in the research. These research results illustrated the relation between the personality of Social Workers, ethical principles and the quality of Social Service using these categories:

- Relationship between Social Worker and client based on trust is a long-term process; worth to spend more time with clients to achieve more goals. If the trust is built between them, than the both are more willing to cooperate and to make changes. $58 \%$ said that trust is the key to success in the work with vulnerable people.

- Achievement of goals: if the Social Worker wants to achieve goals and make changes in the life of the client, it is necessary to pass on ethical principles and be a positive life example how to live in an active way, overcome problems and achieve life goals.

- Respect the rights of the clients: if the Social Worker respects the rights of the clients, than clients are more likely to respect a professional Social Worker. The Social Worker makes an individual plan together with the clients to match their needs, interests and feelings.

- Positive feedback: it is necessary to have a feedback about the Practice work. If Social Workers get positive feedback from the clients with whom they have done good work, it is worthwhile (Schrader-McMillen, Stevard-Brown, 2011).

Bérešová (2016) conducted a study on the relationship between burnout syndrome and the emotional intelligence of Social Workers involved in crisis intervention. In a survey of Social Workers it has detected a high rate of exposure to burnout syndrome. 
Social Workers with high and medium levels of burnout show reduced values of emotional intelligence in individual areas.

\section{Conclusion}

Providing Social Services in Facilities and non-profit organizations means creating a triangle Social Worker - client - social environment/community because they want together to achieve better living conditions on the principle of ethics, morality and human respect. On the other hand, this triangle expresses ethical dilemmas which a Social Worker struggles with in direct contact with clients in order to achieve the well-being of the clients; the interests and priorities of the organization; not to lose one's own interests and dignity. The financial resources in Social Work Practice are very limited; the quality of Social Service suffers from it; do not meet client's needs adequately; a high risk of burnout syndrome; eliminating ethical standards at the workplace in an effort to maintain the viability of the organization/Social Facility.

Social Workers are powerful advocates with the knowledge, skills and values to really change lives. We should use this demographic challenge to build on the experience and assets of older people rather than adopt the unhelpful rhetoric that so often frames the debate. The current crisis is largely viewed through Health Care and population problems, describing older people as bed blockers; but can also be seen as an opportunity to consider the potential to synergize services.

\section{References}

1. BERESOVA A (2016) Burnout of Social Workers working in crisis intervention in relation to emotional intelligence. In: Social Problems of Marginalized Groups. Actual problems in Social Work, Family and children, Roma minority, Disabled people, dependencies, Impacts of economic crisis, Ethical and legal aspects. Martin Luther Institute of Social Work, Bacsky Petrovec, Serbia, St. Elizabeth University of Health and Social Sciences, p. 298. ISBN 978-8680092-19-5.

2. BLOM B, MOREN S (2012) Evaluation of quality in social-work practice. In: Nordic Journal of Social Research [online]. [cited 2017-01-06]. Available at: <https://boap. uib.no/index.php/njsr/article/view/205>. ISSN 1892-2783.

3. GURAN P, BALOGOVA B, MARCIKOVA I, MATEL A (2015) Higher professional training program Professional methods of working in crisis situations. Bratislava: IVPR. p. 62.

4. IFSW / IASSW (2004) Ethics in Social Work: Statement of Principles. Geneva: IFSW. [online]. [cited 2016-12-08]. Available at: http://www.employment.gov.sk/sk/ rodina-socialna-pomoc/socialna-praca/>.

5. SCHADER-McMILLEN A, STEVART -BROWN S (2011) Parenting for mental health: what does the evidence say we need to do? In: Oxford Journals. [online]. Volume 26, Issue suppl 1. Pp. 10-28. [cited 2017-01-06]. Available at: <http://heapro. oxfordjournals.org/content/26/suppl_1/i10. long>. ISSN 1460-2245. 